\title{
Consequences of Land Use and Land Cover Change
}

\section{Introduction}

The U.S. Geological Survey (USGS) Climate and Land Use Change Mission Area is one of seven USGS mission areas that focuses on making substantial scientific " ....contributions to understanding how Earth systems interact, respond to, and cause global change” (Burkett and others, 2011). Using satellite and other remotely sensed data, USGS scientists monitor patterns of land cover change over space and time at regional, national, and global scales. These data are analyzed to understand the causes and consequences of changing land cover, such as economic impacts, effects on water quality and availability, the spread of invasive species, habitats and biodiversity, carbon fluctuations, and climate variability.

USGS scientists are among the leaders in the study of land cover, which is a term that generally refers to the vegetation and artificial structures that cover the land surface. Examples of land cover include forests, grasslands, wetlands, water, crops, and buildings. Land use involves human activities that take place on the land. For example, "grass" is a land cover, whereas pasture and recreational parks are land uses that produce a cover of grass.

\section{Why Study Consequences of Land Use and Land Cover Change?}

Land cover is influenced by changing natural environmental conditions and human activities. Distinguishing changes in land cover due to natural variability as compared to human activities requires understanding how natural and human influences interact. Assessing the consequences of changes in land use and land cover begins with interdisciplinary knowledge of what changes are occurring, what processes are causing the changes, and what the impacts of changes in land use and land cover have been or may be.

Changes in land cover can influence climate and climate, in turn, can influence land use and land cover. These land cover changes affect weather and climate variability by altering biophysical, biogeochemical, and energy exchange processes at local, regional, and global scales.

\section{Biogeochemical -}

Land cover change caused by urban development and the logging of forests, for example, can affect the global carbon budget and have long-term climatic impacts.

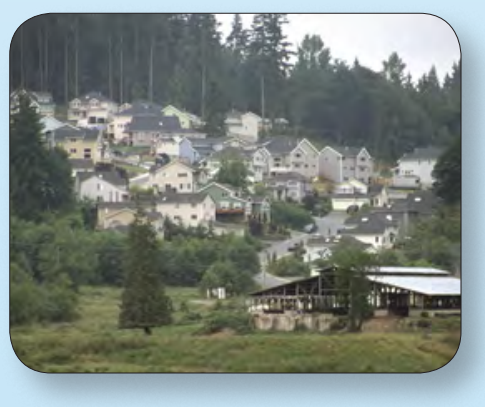

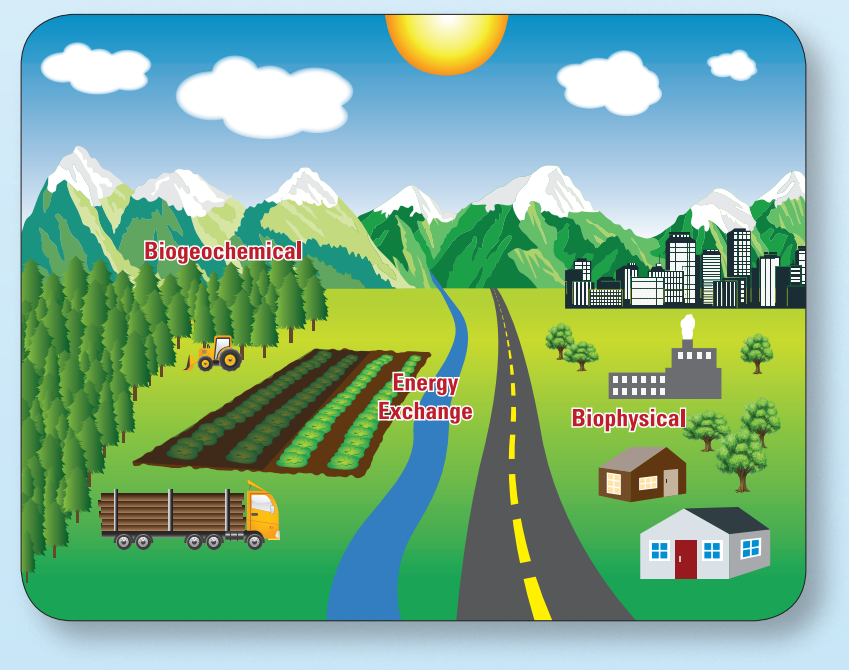
Energy Exchange -
Land cover change can alter vegetative transpiration and surface hydrology, which collectively can determine the parti- tioning of surface heat into latent (hidden) and sensible (measurable) heat fluctuations.

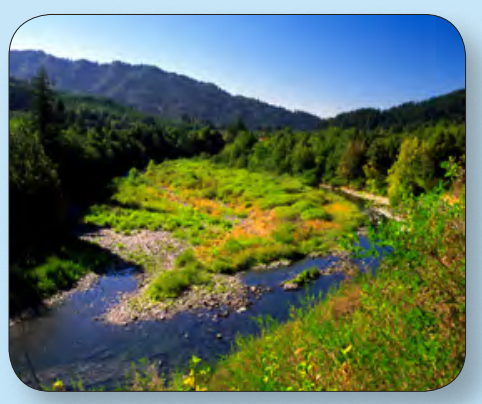

\section{Biophysical -}

Land cover change can modify the reflectance of the land surface, determining the fraction of the Sun's energy absorbed by the surface and thus affecting heat and moisture fluctuations to the atmosphere.

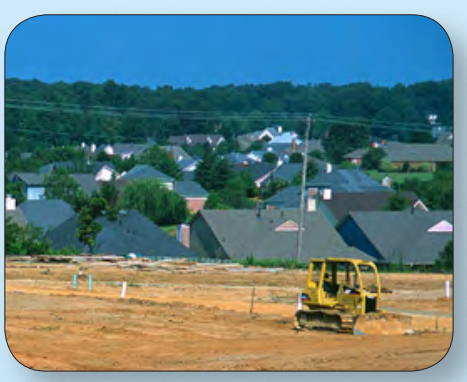


While land change is local in origin, it can have regional and global consequences. USGS scientists use the best land cover information at multiple scales over space and time to understand land cover change and assess the impacts and extent of land change on the Earth.

The following three projects are examples of USGS scientists investigating consequences of land change.

\section{Land Cover and the Earth's Energy Budget}

It is well established that land use and land cover practices affect Earth surface properties, including albedo. Albedo affects the Earth's energy budget by controlling how much incoming solar radiation is absorbed and reflected by the Earth's surface back into space (fig. 1). Fresh snow has a high albedo (high reflection), whereas vegetated surfaces typically have low albedos (low reflection) due to their photosynthetic properties. The term radiative forcing is used to describe the effect of land cover albedo change on the Earth's energy budget. For example, a positive radiative forcing warms the Earth's surface (low reflection), while a negative forcing cools the surface (high reflection).

Using land use and land cover change data from Landsat, USGS scientists and collaborators studied the impact of land use and land cover change from 1973 to 2000 on surface albedo and radiative forcing across the conterminous United States. They have found that radiative forcing due to land change may be underestimated when spatially and temporally explicit datasets are not used. Further, radiative forcing due to recent (1973-2000) land cover albedo change varies in magnitude across the conterminous United States, with the most cooling due to forest loss and the most warming due to conversion of agriculture to other land use and land cover types (Barnes and Roy, 2010). Potential future impacts (2000 to 2050) of projected change in land cover albedo are currently being investigated. This research makes an important contribution to quantifying the role of land change on the climate system and underscores the need for repeat, coast-to-coast, spatially explicit national land cover mapping.

\section{Effects of Land Cover Change on Hydrology}

Interactions between climate and land systems are as unique as the regional and sectorial driving forces behind them (Loveland and others, 2012). Researchers are investigating how current and future land change may alter environmental processes by analyzing (1) primary contemporary trends in land change (use, cover, and condition), (2) land use and land cover sectors and geographic regions that are most affected by weather and climate variability, and (3) how land use practices are adapting to climate change. These studies will contribute to future land management strategies that may require methods that incorporate an evaluation of how climate and land change effects can combine to influence a wide range of social and economic factors, as well as ecological factors such as ecosystem services and effects on hydrologic systems.

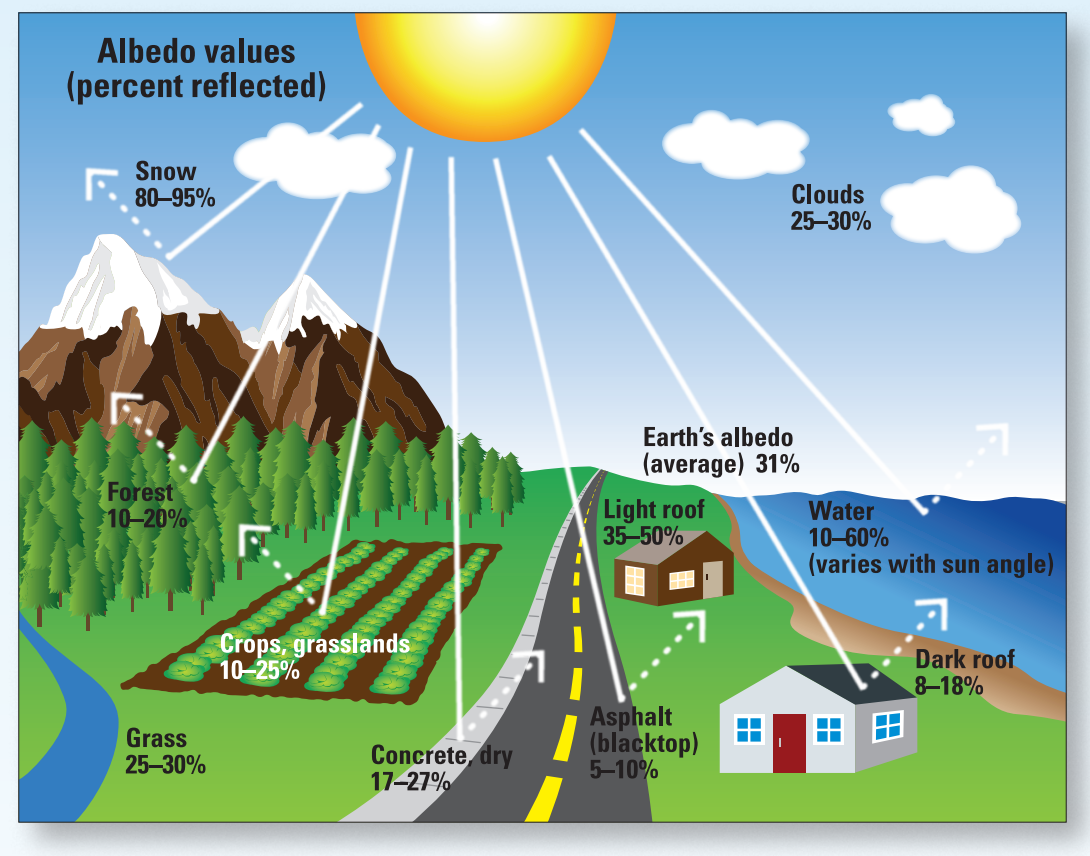

Figure 1. Albedo is the fraction of the Sun's energy reflected from the Earth's surface and its atmosphere. The amount of energy that is absorbed, emitted, or reflected varies geographically and affects the Earth's climate system in such a way as to cause fluctuations in temperature, winds, ocean currents, and precipitation. Illustration by Sarah Jenkins. 
This research effort is also contributing to the development of a framework for ongoing national assessments. For example, USGS scientists are currently analyzing geographic frameworks in conjunction with hydroclimatic research to further understand the links between climate, land cover change, and hydrology by analyzing trends in maximum streamflows (fig. $2 A$ and $2 B$ ) (Robert Holmes, USGS, written commun., 2009).

Characterizing land change and hydrologic trends will help determine the effect of urbanization on flood peaks and provide more accurate and relevant estimates of the expected frequency of floods.

\section{Land Cover Change due to Hydrocarbon Extraction}

High demands in energy resources, especially for cleaner burning energy, coupled with the relatively recent technological advances in accessing hydrocarbon-rich geologic formations, has led to an increased effort to locate and extract natural gas from various sources around the country. One of those formations, the Marcellus Shale, is currently the focus of extensive drilling and production in the Allegheny Plateau, extending from New York to West Virginia.

Exploration and extraction of natural gas in Marcellus Shale result in a unique land surface that alters patterns on the landscape, particularly forests. Using high spatial resolution imagery from the National Agriculture Imagery Program (National Agriculture Imagery Program, 2012), USGS scientists are mapping access roads, gas drilling pads, and pipelines to examine changes in local habitat, water quality, and landscape quality as a result of natural gas extraction (fig. 3). Changing land use has the potential to have serious, sometimes unforeseen, effects on our lives and well-being. Developing a better understanding of the unintended consequences of land use and land cover changes, so that informed decisions can be made, is the objective of this USGS research (Slonecker and others, 2012).

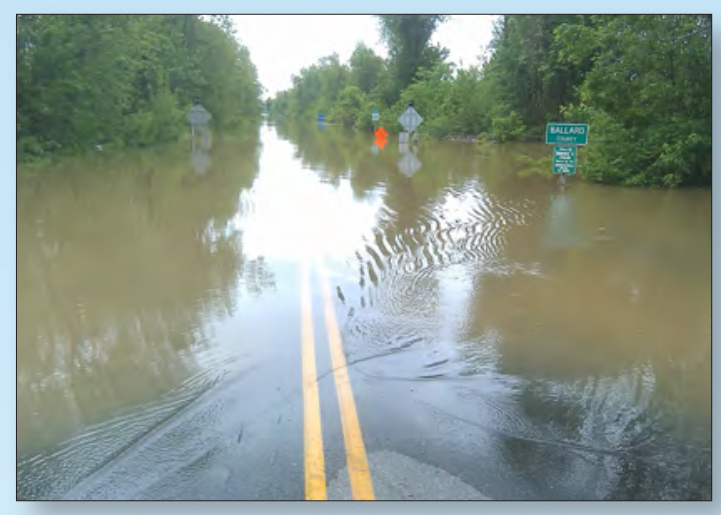

Figure 2A. Flooding across U.S. Highway 60 in the Ohio River overflow area, east of Cairo, Illinois, in 2011. Photograph by Todd Koenig, USGS.

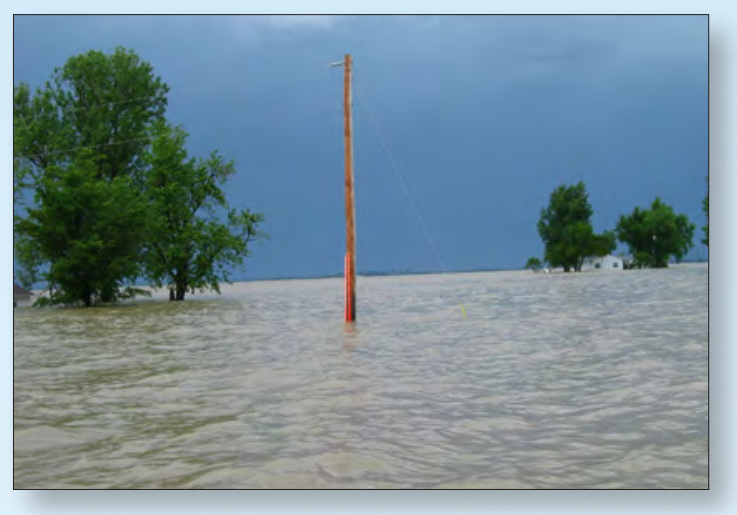

Figure 2B. Birds Point-New Madrid Floodway located on the west bank of the Mississippi River in southeast Missouri in 2011. Photograph by Todd Koenig, USGS.

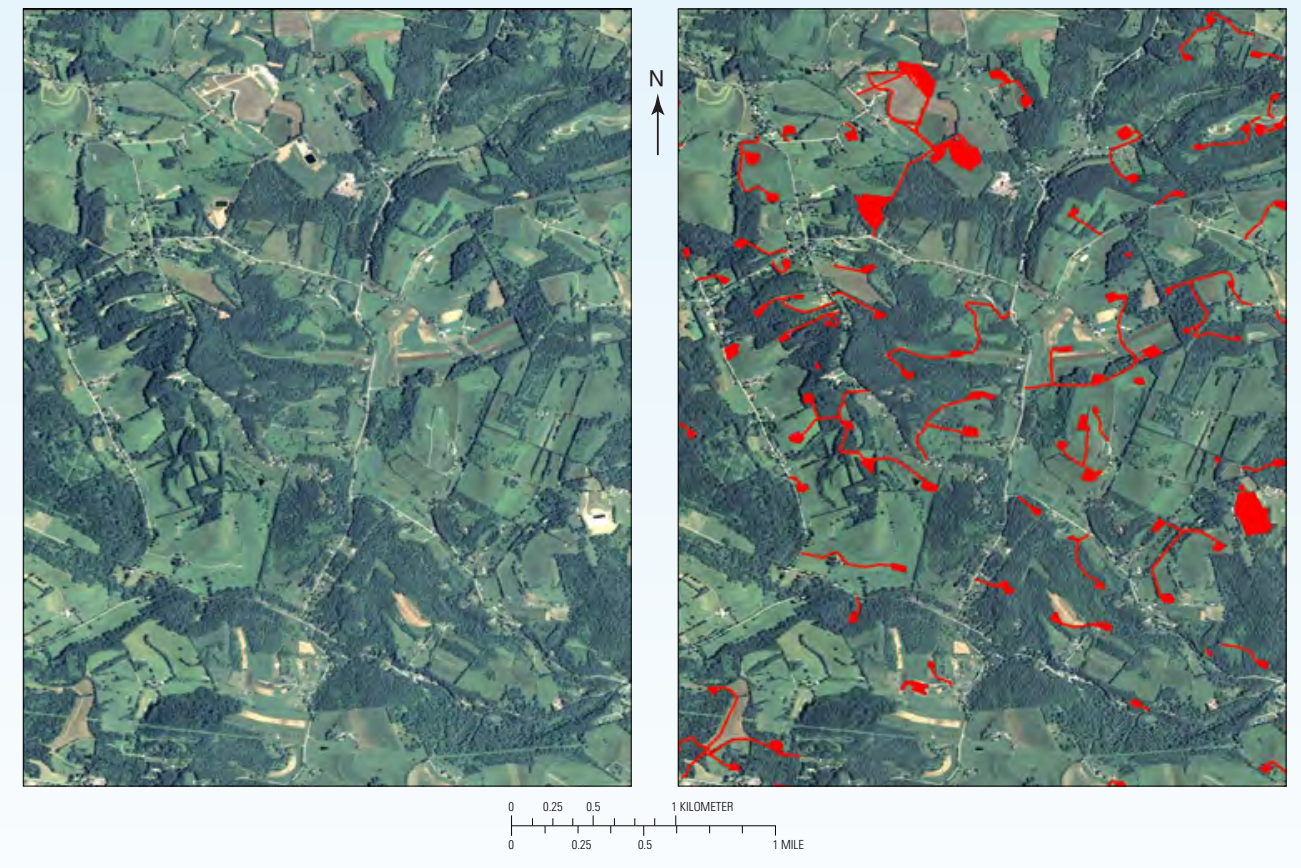

Figure 3. A forested landscape in Pennsylvania (left) illustrating the spatial distribution of roads, well pads, and pipelines (in red on right) related to hydrocarbon exploration and development. Photo from the National Agriculture Imagery Program (2012). 


\section{Summary}

The focus on the consequences of land use and land cover change at the USGS has evolved to be a principal research area, especially as a global change. The effects of a changing planet are not limited to those caused by atmospheric and climate changes but also to more subtle changes in land use and land cover that impact patterns of vegetation and hydrology.

Research that advances understanding the consequences of land use and land cover change should help to better inform policies directed at responding to an ever changing world.

\section{References Cited}

Barnes, C.A., and Roy, D.P., 2010, Radiative forcing over the conterminous United States due to contemporary land cover land use change and sensitivity to snow and interannual albedo variability: Journal of Geophysical Research, v. 115, 14 p., available at $h t t p: / / d x . d o i . o r g / 10.1029 / 2010 J G 001428$.

Burkett, V.R., and others, 2011, Public review draft; USGS global change science strategy: A framework for understanding and responding to climate and land-use change, U.S. Geological Survey Open-File Report 2011-1033, 32 p., available at $h t t p: / / p u b s . u s g s . g o v / o f / 2011 / 1033$.

Loveland, Thomas, Mahmood, Rezaul, Patel-Weynand, Toral, Karstensen, Krista, Beckendorf, Kari, Bliss, Norman, and Carleton, Andrew, 2012, National climate assessment technical report on the impacts of climate and land use and land cover change: U.S. Geological Survey Open-File Report 2012-1155, 87 p., available at http://pubs.usgs.gov/ of/2012/1155/.

National Agriculture Imagery Program, 2012, Information sheet: U.S. Department of Agriculture, available at http://www.fsa.usda.gov/Internet/FSA_File/naip_2012_ infosheet.pdf.

Slonecker, E.T., Milheim, L.E., Roig-Silva, C.M., Malizia, A.R., Marr, D.A., and Fisher, G.B., 2012, Landscape consequences of natural gas extraction in Bradford and Washington Counties, Pennsylvania, 2004-2010: U.S. Geological Survey Open-File Report 2012-1154, 36 p., available at http://pubs.usgs.gov/of/2012/1154/.

\section{Contacts}

E. Terrence Slonecker

U.S. Geological Survey

12201 Sunrise Valley Drive

Reston, VA 20192

tslonecker@usgs.gov

Christopher Barnes

ARTS, Contractor to the U.S. Geological Survey

Earth Resources Observation and Science

(EROS) Center

Sioux Falls, SD 57198

barnes@usgs.gov

Krista Karstensen

U.S. Geological Survey

Earth Resources Observation and Science

(EROS) Center

Sioux Falls, SD 57198

kkarstensen@usgs.gov

Lesley Milheim

U.S. Geological Survey

12201 Sunrise Valley Drive

Reston, VA 20192

Imilheim@usgs.gov

Coral Roig-Silva

U.S. Geological Survey

12201 Sunrise Valley Drive

Reston, VA 20192

croig@usgs.gov 